\title{
Letter to The Editor: COVID-19: Looking South and East in the World for Guidance
}

\author{
Kokila Lakhoo ${ }^{1}$ - Diana Farmer ${ }^{2}$
}

Published online: 5 June 2020

(C) Société Internationale de Chirurgie 2020

\section{Dear Editor,}

If the pandemic has taught us anything, it is the reminder that disease knows no artificial boundaries. Disease and public health are truly global concerns, and there is much that we can learn from one other. No country in the world can lay claim to having effectively mastered the social or medical implications of the pandemic. While technologically advanced high-income countries might have access to more critical care beds or ventilators, our low- and middleincome country colleagues have humbled us with their forward-thinking public health measures, border controls and contact tracing.

Historically charts as displayed in Fig. 1 usually show a reversal of data with the low income countries (LIC) at the top of the graphs for high rates of mortality and morbidity. High-income countries (HIC) such as the USA and the UK who currently have the highest death rates have taken taking lessons from China and Italy. However, taking lessons from continents with low death rates such as Africa and South America (Fig. 1) who have embraced a rigorous public health approach may add value as demonstrated in the graph (Fig. 1). Countries with limited or no high-tech resources have fully understood that controlling the pandemic facing their countries demanded strict use of the public health route which provided a better means of containing the disease than using a high-tech approach. Africa countries are classic examples of a success story at this point in the pandemic [1].

Kokila Lakhoo

kokila.lakhoo@paediatrics.ox.ac.uk

1 Oxford, UK

2 UC Davis, Davis, USA
The natural disaster in Haiti [2] was a classical lesson to us that well-meaning involvement from high-income countries was unable to achieve the outcomes we were all hoping for. Time and time again, the message from the southeast region of the world during disaster relief to the northwest region of the world is to listen, embrace and work with the local LIC teams so that the goal of alleviating human suffering may be achieved in a sustainable cost effective manner.

We have seen many examples of instant innovation and creativity in the face of limited resources in low income countries such as low costs ventilators and alternatives for delivering oxygen, PPE (personal protective equipment) from plastic bags, masks from banana leaves and most of all community spirit.

As surgeons from high-income countries who have spent a considerable part of our careers involved in LMICs and global surgery, the value of skill sharing, interchange and intellectual exchanges between our countries is priceless. We are all physicians, trained in a common tradition. The tie that binds us is human suffering. It knows no boundaries and no end. The loss of a child or a parent to infectious disease or to a road traffic accident is tragic, heart-breaking and destabilizing no matter where one lives and loves. Let us reflect and use this worldwide pandemic with its tragic loss of life to come together in the service of humanity that also knows no artificial boundaries. 


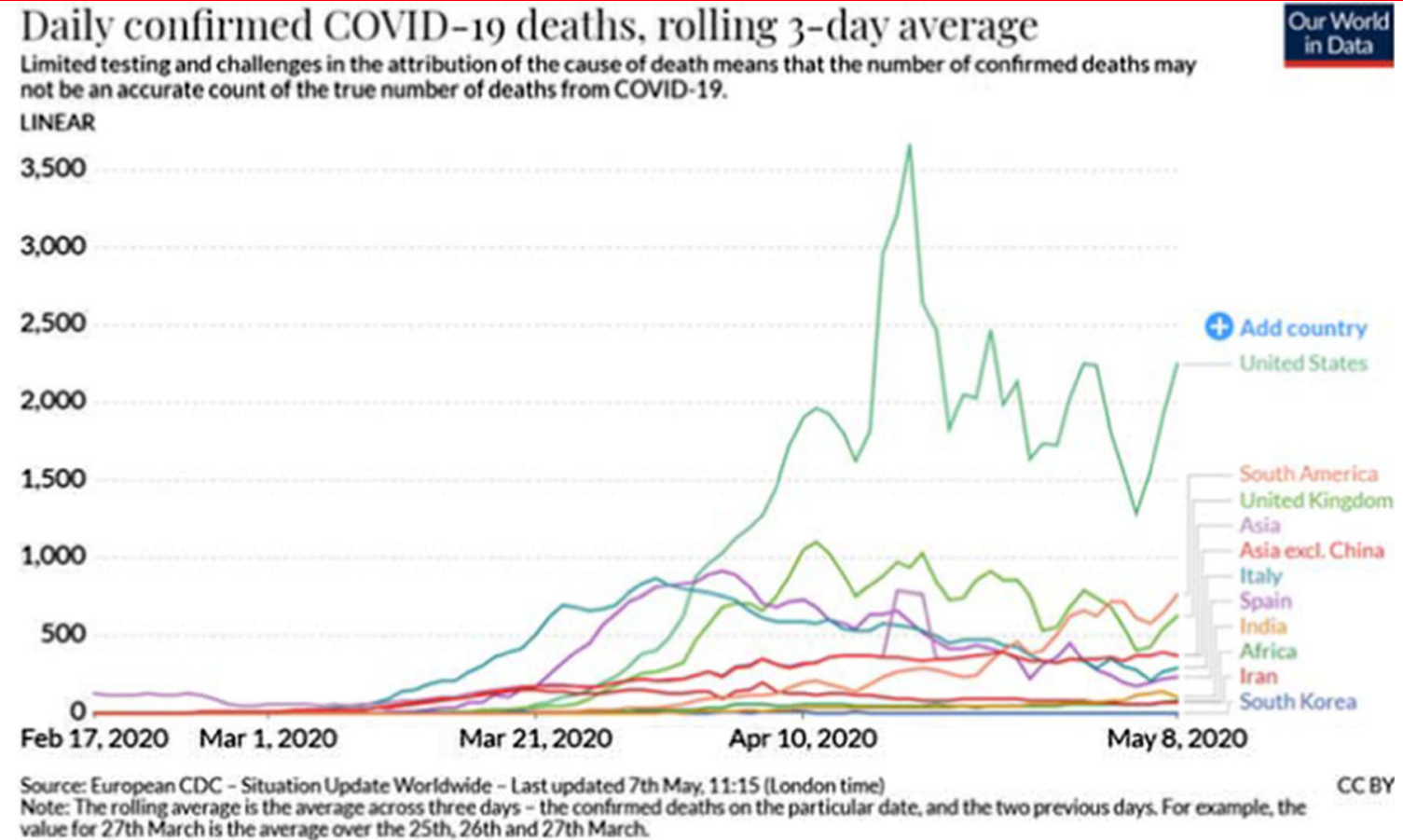

Fig. 1 Data on COVID-19 deaths

\section{References}

1. El-Sadr WM, Justman J (2020) Perspective: Africa in the path of Covid-19. NEJM. https://doi.org/10.1056/NEJMp2008193

2. Hunt MR, Chung R, Durocher E, Henrys JH (2015) Haitian and international responders' and decision-makers' perspectives regarding disability and the response to the 2010 Haiti earthquake. Global Health Action 8(1):27969. https://doi.org/10.3402/gha.v8. 27969

Publisher's Note Springer Nature remains neutral with regard to jurisdictional claims in published maps and institutional affiliations. 